\title{
PERBEDAAN DAYA DUKUNG FONDASI DANGKAL DI TANAH GAMBUT DENGAN DAN TANPA MENGGUNAKAN EPOXY DI KALIMANTAN
}

\author{
Avira Natasyah Wihelmina ${ }^{1}$ dan Chaidir Anwar Makarim ${ }^{2}$ \\ ${ }^{1}$ Program Studi Sarjana Teknik Sipil, Universitas Tarumanagara, Jl. Letjen S. Parman No.1 Jakarta \\ avira.325150094@stu.untar.ac.id \\ ${ }^{2}$ Program Studi Sarjana Teknik Sipil, Universitas Tarumanagara, J1. Letjen S. Parman No.1 Jakarta \\ chaidir259@gmail.com
}

Masuk:11-01-2021, revisi: 01-02-2021, diterima untuk diterbitkan: 11-02-2021

\begin{abstract}
The construction of residential houses in East Kalimantan will continue to increase, if we do not know the nature and characteristics of the peat soil itself, there will be many problems or construction failures. Peat soil or better known as peat soil has a low soil bearing capacity and a large settlement. This study aims to determine the bearing capacity and subsidence in the soil in East Kalimantan when using a shallow square foundation measuring $2 \mathrm{~m} \times 2 \mathrm{~m}$ with a depth of $1.5 \mathrm{~m}$ and the efficiency of the cost of making the foundation when using epoxy and not using epoxy, as a paint that protects the foundation layer from high acidity of peat soils.
\end{abstract}

Keywords: peat;bearing capacity;epoxy.

\begin{abstract}
ABSTRAK
Pembangunan konstruksi rumah tinggal di Kalimantan timur akan terus meningkat, apabila kita tidak mengetahui sifat dan karakteristik dari tanah gambut itu sendiri maka akan terjadi banyak masalah atau kegagalan konstruksi. Tanah gambut atau yang lebih dikenal dengan nama peat soil memiliki daya dukung tanah yang rendah dan penurunan yang besar. Penelitian ini bertujuan untuk mengetahui daya dukung dan penurunan pada tanah dikalimantan timur apabila menggunakan fondasi dangkal bujur sangkar yang berukuran $2 \mathrm{~m} \times 2 \mathrm{~m}$ dengan kedalaman 1,5m dan efisiensi harga pembuatan fondasi apabila menggunakan cat epoxy dan tidak menggunakan cat epoxy,sebagai cat yang melindungi lapisan fondasi dari kadar keasaman tanah gambut yang tinggi.
\end{abstract}

Kata kunci: gambut; daya dukung; epoxy.

\section{PENDAHULUAN}

Bangunan rumah tinggal adalah salah satu dari kebutuhan setiap makhluk hidup, dimana bagunan ini dijadikan sebagai tempat tinggal dari setiap manusia. Pada suatu daerah dikalimantan timur akan dibangun sebuah rumah tinggal yang memiliki luas $225 \mathrm{~m}$ persegi. Keberadaan Tanah lunak ini memberikan banyak kerugian seperti kurangnya daya dukung yang bisa menyebabkan mahalnya desain perencanaan, angka keamanan yang kecil dan bisa berbahaya dan memberikan kerugian seperti keretakan dinding bangunan akibat fondasi yang tidak kuat terhadap tingkat keasaman pada air tanah tersebut. Dikarenakan tingkat asam yang tinggi pada tanah ini maka pemakaian cat epoxy pada lapisan fondasi cukup menjadi solusi.

Tujuan dilakukannya penelitian ini adalah untuk mengetahui apakah daya dukung tanah menggunakan fondasi dangkal dapat memenuhi syarat, dan berapa besar biaya yang di butuhkan untuk membuat fondasi menggunakan epoxy dan membuat fondasi tanpa menggunakan epoxy.

\section{Tanah gambut}

Tanah gambut dalam konstruksi menjadi permasalahan, karena daya dukungnya yang rendah menyebabkan kerugian, mulai dari kerugian biaya konstruksi yang semakin mahal hingga rendahnya angka keamanan dan tanah gambut sendiri memiliki kadar ph yang rendah dan menyebabkan kandungan mineralnya menjadi asam.

Menurut Construction Research Institute of Malaysia (2015), Gambut juga ditemukan di iklim tropis, dimana kondisinya memungkinkan untuk pembentukan gambut. Lahan gambut tropis tersebar di beberapa wilayah Afrika, dan bagian dari Amerika Tengah, namun dua per tiga dari total wilayahnya dilaporkan berada di Asia Tenggara. Wilayah lahan gambut tropis terletak di pulau Kalimantan dan Sumatera. Selain itu juga ditemukan di Malaysia, Vietnam, Thailand dan Filipina. 


\section{Fondasi dangkal}

Fondasi dangkal memiliki beberapa jenis fondasi yaitu fondasi telapak, fondasi cakar ayam, fondasi sarang labalaba, fondasi gasing, fondasi grid, dan fondasi hypaar. Namun fondasi telapak adalah salah satu fondasi dangkal yang paling sering digunakan untuk berbagai tipe tanah pada sebuah konstruksi bangunan khususnya rumah tinggal. Perencanaan struktur fondasi didasarkan pada beban momen dan beban aksial yang terjadi sehingga mengakibatkan terjadinya gaya tekan pada dasar fondasi yangdisalurkan ke tanah.

\section{Daya dukung tanah}

Besaran Daya dukung pada tanah adalah besar tekanan yang biasa disebut juga sebagai kemampuan pada tanah untuk menerima beban luar sehingga menjadi stabil. Besar Kapasitas daya dukung fondasi dangkal memiliki hubungan dengan bagian perancangan di dalam bidang geoteknik. Beberapa kriteria perancangan yang biasa dibuat adalah nilai kapasitas daya dukung pada tanah harus lebih besar atau sama dengan nilai beban luar yang ditransfer melalui fondasi ke tanah yang berada dibawah pondasi. Metode Terzaghi mempersiapkan rumus daya dukung tanah yang memperhitungkan keadaan ultimate bearing capacity, artinya: apabila suatu batas nilai dilampaui dapat menimbulkan runtuhan (collapse). Oleh karena itu daya dukung yang sesuai dengan ijin (allowable bearing capacity) harus lebih kecil daripada ultimate bearing capacity. Daya dukung batas (qult, ultimate bearing capacity; $\mathrm{kg} / \mathrm{cm} 2, \mathrm{t} / \mathrm{m} 2$ ) tanah yang terdapat pada bawah beban fondasi sangat bergantung pada kekuatan geser (shear strength). Nilai daya dukung tanah yang diijinkan (qa, allowable bearing capacity) untuk sebuah rancangan bangunan fondasi ikut melibatkan beberapa faktor karakteristik kekuatan dan deformasi. Nilai daya dukung ijin (allowable bearing capacity, qa) sangat tergantung pada sebesar apa nilai Faktor Keamanannya (F) yang dipilih. Umumnya nilai Faktor Keamanan yang biasa dipilih yaitu 2 sampai dengan 5, sampai besar daya dukung yang diijinkan, dapat dilihat seperti pada gambar 1 dan gambar 2 dibawah, berikut ini:

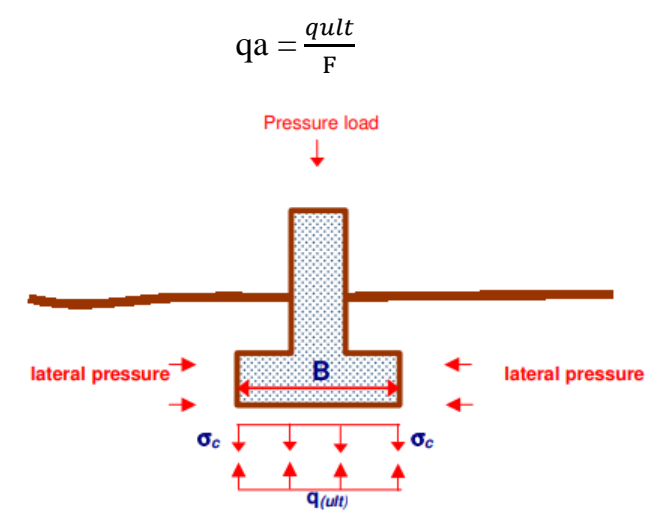

Gambar 1. Gaya yang bekerja pada sistem fondasi (Zakaria, 2006)

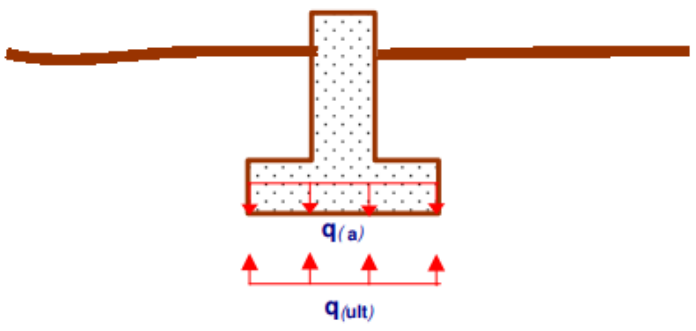

Gambar 2. Hubungan q(a) dan q(ult) pada fondasi (Zakaria, 2006)

Untuk menghitung besaran kapasitas dayadukung menggunakan metode Terzaghi dapat dilihat pada tabel 1 dibawah ini. 
Tabel 1. Kapasitas dayadukung tanah untuk beberapa jenis fondasi menurut cara Terzaghi.

\begin{tabular}{ll}
\hline Jenis pondasi & Kapasitas daya dukung (Terzaghi) \\
\hline Lajur/menerus & qult $=$ c.Nc + q.Nq $+0,5 \gamma \mathrm{B} \mathrm{N} \gamma$ \\
\hline Segi empat & qult $=1,3$ c.Nc + q.Nq $+0,4 \gamma \mathrm{B} \mathrm{N \gamma}$ \\
\hline Lingkaran & $\mathrm{q} u l t=1,3 \mathrm{c} . \mathrm{Nc}+\mathrm{q} \cdot \mathrm{Nq}+0,3 \gamma \mathrm{B} \mathrm{N} \gamma$ \\
\hline
\end{tabular}

\section{Penurunan tanah}

Jika lapisan tanah diberikan beban, maka tanah akan mengalami penurunan. Penurunan yang disebabkan oleh pengurangan rongga pori dan air di dalam tanah tersebut. Tanah didefinisikan secara umum adalah kumpulan dari bagian-bagian yang padat dan tidak terikat antara satu dengan yang lain (diantaranya mungkin material organik) rongga-rongga diantara material tersebut berisi udara dan air (Verhoef, 1994). Keluarnya air dan berkurangnya volume dari tanah tersebut menyebabkan naiknya daya dukung tanah dasar. Pada kasus tanah lempung yang berpemeabilitas rendah, tegangan air pori berlebih membutuhkan waktu yang cukup lama untuk teredisipasi. Ada dua jenis penurunan konsolidasi yaitu konsolidasi normal (normally consolidated) dan konsolidasi berlebih (over consolidated) Berdasarkan teori Terzaghi tentang konsolidasi satu dimensi, untuk tanah terkonsolidasi normal dapat dihitung dengan persamaan berikut :

$$
S_{c}=\frac{C_{C}}{1+e_{0}} H \log \left(\frac{\mathrm{Po}^{\prime}+\Delta \mathrm{p}}{\mathrm{Po} \prime}\right)
$$

dengan $\mathrm{Sc}=$ penurunan konsolidasi, $\mathrm{Cc}=$ nilai compression index, $\mathrm{e}_{0}=$ Void Ratio awal, $\mathrm{H}=$ Tinggi awal terkonsolidasi, $\mathrm{Po}^{\prime}=$ Tegangan overburden efektif, $\mathrm{Po}^{\prime}+\Delta \mathrm{p}=$ Tegangan tanah akhir, yaitu tegangan tanah awal + tegangan akibat beban luar.

Sedangkan untuk tanah yang terkonsolidasi berlebih, penurunan dapat dihitung dengan persamaan berikut untuk $\left(\mathrm{Po}^{\prime}+\Delta \mathrm{p}>\mathrm{Pc}\right):$

$$
S_{c}=\frac{C_{c}}{1+e_{0}} H \log \left(\frac{\mathrm{Pc}^{\prime}}{\mathrm{Po}^{\prime}}\right)+\frac{C_{c}}{1+e_{0}} H \log \left(\frac{\mathrm{Po}^{\prime}+\Delta \mathrm{p}}{\mathrm{Pc}^{\prime}}\right)
$$

Apabila $\left(\mathrm{Po}^{\prime}+\Delta \mathrm{p}<\mathrm{Pc}\right):$

$$
S_{c}=\frac{C_{S}}{1+e_{0}} H \log \left(\frac{\mathrm{Po}^{\prime}+\Delta \mathrm{p}}{\mathrm{Po}^{\prime}}\right)
$$

dengan Pc' = Tegangan Prakonsolidasi.

\section{Lapisan tanah compressible}

Untuk tebal lapisan tanah compressible yang diperhitungkan adalah tanah yang bisa mengalami pemampatan proses konsolidasi primer, yaitu yang memiliki nilai N-SPT > 10 dianggap sudah tidak dapat mengalami konsolidasi, dapat dilihat pada tabel. 2 dibawah ini.

Tabel 2. Hubungan N-SPT terhadap konsistensi tanah lempung (Terzaghi dan Peck, 1967)

\begin{tabular}{cccc}
\hline Consistency & $\begin{array}{c}\text { Unconfined Compression } \\
\text { Strength }, q_{u}\left(\mathrm{kN} / \mathrm{m}^{2}\right)\end{array}$ & $\begin{array}{c}\text { N-SPT } \\
(\text { blows per } f t)\end{array}$ & $\begin{array}{c}\text { Waturated Unit } \\
\left(\mathrm{kN} / \mathrm{m}^{3}\right)\end{array}$ \\
\hline Very Soft & $0-25$ & $0-2$ & $<16$ \\
Soft & $25-50$ & $2-4$ & $16-19$ \\
\hline
\end{tabular}


Lanjutan Tabel 2. Hubungan N-SPT terhadap konsistensi tanah lempung (Terzaghi dan Peck, 1967)

\begin{tabular}{cccc}
\hline Medium & $50-100$ & $4-8$ & $17-20$ \\
\hline Stiff & $100-200$ & $8-15$ & $18-20$ \\
Very Stiff & $200-400$ & $15-30$ & $19-22$ \\
Hard & $>400$ & $>30$ & $>20$ \\
\hline
\end{tabular}

\section{Waktu penurunan konsolidasi}

Hal yang mempengaruhi waktu penurunan adalah panjang lintasan air untuk terdisipasi. Pada tanah yang terkonsolidasi tidak dengan menggunakan $P V D$, pengaliran yang terjadi hanya arah vertikal. Menurut Terzaghi dalam (B. M. Das), lama waktu konsolidasi dapat dicari dengan persamaan berikut:

$$
t=\frac{T_{v}\left(H_{d r}\right)^{2}}{C_{v}}
$$

dengan $\mathrm{t}=$ waktu konsolidasi, $\mathrm{Tv}=$ faktor waktu, $\mathrm{Hdr}=$ panjang aliran air, $\mathrm{Cv}=$ koefisien konsolidasi vertikal . Untuk derajat konsolidasi antara 0-60\% dirumuskan dengan :

$$
U=\left(2 \sqrt{\frac{T_{v}}{\pi}}\right) 100 \%
$$

dengan $\mathrm{U}=$ derajat konsolidasi, $\mathrm{TV}=$ faktor waktu.

\section{Perhitungan rencana anggaran biaya}

Rencana anggaran biaya (RAB) adalah suatu dokumen yang berisi komponen masukan (input) dari sebuah kegiatan besaran biaya dari masing-masing komponen. RAB merupakan penjabaran lebih lanjut dari unsur perkiraan biaya dalam kerangka acuan kegiatan (Term Of Reference).Jadi rencana anggaran biaya bangunan atau RAB adalah perhitungan biaya bangunan berdasarkan gambar bangunan dan spesifikasi pekerjaan dan konstruksi yang akan di bangun, sehingga dengan adanya RAB dapat dijadikan sebagai acuan pelaksanaan pekerjaan nantinya.

\section{Epoxy}

Cat anti korosi berbahan dasar bitumen warna hitam khusus coating tiang pancang/metal sebelum di tanam ke dalam air atau tanah. Epoxy coating untuk mengisi celah-celah keretakan lantai beton, dinding beton, dll. Berfungsi sebagai dempul atau waterproofing untuk meratakan permukaan sebelum finishing.

\section{METODE PENELITIAN}

Dalam penelitian ini dilakukan beberapa tahapan sebagai berikut :

1. Tahapan pertama, melakukan pengumpulan data data parameter tanah, data beban di atas tanah, dan data biaya persatuan bahan dan tenaga.

2. Tahapan kedua, pengumpulan informasi yang berkaitan dengan perhitungan daya dukung tanah, penurunan dan perhitungan rencana anggaran biaya.

3. Tahapan ketiga, melakukan korelasi data pada parameter tanah dan pendekatan dari data-data yang ada dan dibutuhkan untuk perhitungan daya dukung dan penurunan tanah.

4. Tahapan keempat, melakukan analisis untuk daya dukung tanah, penurunan dan rencana anggaran biaya.

5. Tahapan kelima, penjabaran hasil perencanaan fondasi dangkal sesuai dengan yang diinginkan atau tidak. Setelah itu didapatkan hasil kesimpulan apakah fondasi dangkal dengan menggunakan lapisan epoxy dapat digunakan ditanah gambut atau tidak.

\section{HASIL DAN PEMBAHASAN}

Pada perencanaan ini digunakan 3 titik bor yang berbeda serta dilakukan pengambilan sampel pada ketiga titik tersebut. Analisis dilakukan dengan geometri timbunan pada BH-1. Setelah dilakukan korelasi parameter pada data tanah, akan dilanjutkan dengan perhitungan tinggi timbunan actual (Hinitial) dengan Hfinal yang sudah 
direncanakan. Data korelasi timbunan dari BH-1, BH-2 dan BH-3 dapat dilihat pada tabel 3 dibawah ini, sebagai berikut :

Tabel 3. Data parameter tanah

\begin{tabular}{lccccccccc}
\hline Soil & $\begin{array}{c}\text { Elevation } \\
(\mathrm{m})\end{array}$ & $\begin{array}{c}\Upsilon \text { sat } \\
\left(\mathrm{kN} / \mathrm{m}^{3}\right)\end{array}$ & $\mathrm{e}$ & $\begin{array}{c}\mathrm{Po} \\
\left(\mathrm{kN} / \mathrm{m}^{2}\right)\end{array}$ & $\mathrm{Cc}$ & $\begin{array}{c}\mathrm{Cu} \\
\left(\mathrm{kN} / \mathrm{M}^{2}\right)\end{array}$ & OCR & $\begin{array}{c}\mathrm{Pc} \\
\left(\mathrm{kN} / \mathrm{m}^{2}\right)\end{array}$ \\
\hline CLAY & 0 & 1,8 & 17,212 & 0,45 & 15,49 & 0,115 & 30 & & \\
CLAY & 1,8 & 4 & 17,212 & 0,55 & 37,92 & 0,23 & 32,688 & 10,685 & 405,134 \\
CLAY & 4 & 6 & 16,615 & 1,103 & 52,46 & 0,866 & 39,226 & 3,5969 & 188,709 \\
CLAY & 6 & 8 & 15,928 & 0,55 & 65,01 & 0,23 & 26,151 & 4,1828 & 271,917 \\
SILT & 8 & 10 & 15,481 & 1,1 & 76,42 & 0,47 & 13,075 & 1,9624 & 149,969 \\
SILT & 10 & 14 & 15,978 & 1,1 & 93.86 & 0,47 & 13,075 & 2,1306 & 199,980 \\
SILT & 14 & 16 & 15,196 & 1,5 & 111 & 0,686 & 6,37 & 1,9809 & 219,899 \\
SILT & 16 & 18 & 17,299 & 1,5 & 123,5 & 0,686 & 13,075 & 0,8693 & 107,370 \\
SILT & 18 & 20 & 17,318 & 1,5 & 138,1 & 0,686 & 6,537 & 0,3886 & 53,685 \\
SILT & 20 & 22 & 17,318 & 1,5 & 152,8 & 0,686 & 19,613 & 1,0544 & 161,080 \\
SILT & 22 & 28 & 17,318 & 1,5 & 182 & 0,686 & 26,151 & 2,1506 & 391,503 \\
SILT & 28 & 30 & 17,358 & 1,5 & 211,4 & 0,686 & 26,151 & 1,0167 & 214,892 \\
SILT & 30 & 32 & 17,279 & 1,5 & 226 & 0,686 & 71,915 & 2,6151 & 590,985 \\
\hline
\end{tabular}

Perhitungan daya dukung tanah jika menggunakan fondasi bujur sangkar berukuran $2 \mathrm{~m}$ x $2 \mathrm{~m}$ dengan kedalaman 1,5m seperti pada gambar.3 dibawah ,yaitu sebagai berikut:

a. Design Fondasi Dangkal

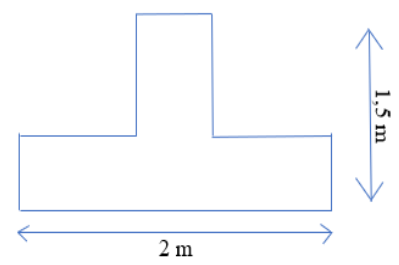

Gambar.3 Design Fondasi Dangkal

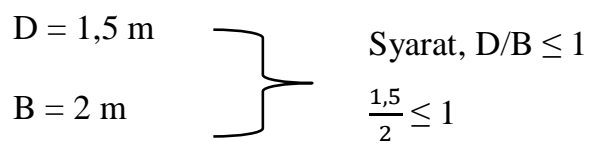

Nilai Beban yang digun $0,75 \leq 1$ (ok)

$\mathrm{Pu}=21,38 \mathrm{kN}=2,180$ ton

$\mathrm{Mu}=14,58 \mathrm{kNm}=1,487$ tonm

$\frac{P}{2 m \times 2 m} \times 0,1=\frac{P}{(2 m+z) x(2 m+z)}$

$(2+z)^{2}=2^{2} \times 10$

$2+\mathrm{z}=2 \sqrt{10}$ 


$$
\begin{aligned}
& \mathrm{z}=(\sqrt{10}-1) \times 2 \\
& \mathrm{z}=4,32 \mathrm{~m} \\
& \bar{q}=\gamma \text { sat } \times \mathrm{D}+\text { efektif } \mathrm{z}=1,1 \times 1+(0,1 \times 0,5)=1,15 \mathrm{ton} / \mathrm{m}^{2} \\
& M=0(1,5 \mathrm{~m})+1,487 \text { tonm }=1,487 \text { tonm } \\
& \mathrm{Hc}=0,5(1,5 \mathrm{~m}) \times \tan \left(45+\frac{33}{2}\right)=0,4604 \mathrm{~m}
\end{aligned}
$$

a) Diagram Tegangan

$$
\begin{aligned}
& \sigma=\frac{V}{A} \pm \frac{M}{W} \\
& \quad=\frac{2,180}{2 \times 2} \pm \frac{1,487}{\frac{1}{6} \times 2 \times 2 \times 2} \\
& \sigma \max =1,66 \mathrm{t} / \mathrm{m}^{2} \\
& \sigma \min =0,57 \mathrm{t} / \mathrm{m}^{2}
\end{aligned}
$$

b) Daya dukung Terzaghi

\section{Longterm:}

$$
\begin{aligned}
\mathrm{q}=1,15 \mathrm{t} / \mathrm{m}^{2} \\
\mathrm{c}=2,48 \mathrm{t} / \mathrm{m}^{2} \\
\phi=33^{\circ} \rightarrow \mathrm{Nc}=48,75 \\
\mathrm{~N}_{\mathrm{q}}=33 \\
\mathrm{~N}_{\gamma}=31,93
\end{aligned}
$$

$$
\begin{aligned}
& \text { qult }=1,3 \mathrm{c} \cdot \mathrm{Nc}+\mathrm{q} \cdot \mathrm{Nq}+0,4 \gamma \mathrm{B} \mathrm{N} \gamma \\
& \mathrm{qult}=1,3(2,48)(48,75)+(1,15)(33)+0,4(1,1)(2)(31,93) \\
& \mathrm{qult}=223,218 \mathrm{t} / \mathrm{m}^{2}
\end{aligned}
$$

$$
\begin{aligned}
\text { qall } & =\text { qult } / \mathrm{SF} \\
\mathrm{q} \text { all } & =223,218 / 3 \\
& =74,406 \mathrm{t} / \mathrm{m}^{2} \rightarrow \mathrm{qall} \geq \sigma \max \\
& \quad 74,406 \mathrm{t} / \mathrm{m}^{2} \geq 1,66 \mathrm{t} / \mathrm{m}^{2}(\text { ok) }
\end{aligned}
$$

Shortterm:

$$
\begin{aligned}
& \mathrm{Su}=4 \mathrm{t} / \mathrm{m}^{2} \\
& \begin{array}{l}
\phi=0^{\circ} \rightarrow \mathrm{Nc}=5,71 \\
\mathrm{~N}_{\mathrm{q}}=1 \\
\mathrm{~N}_{\gamma}=0
\end{array} \\
& \mathrm{qult}=1,3 \mathrm{c} \cdot \mathrm{Nc}+\mathrm{q} \cdot \mathrm{Nq}+0,4 \gamma \mathrm{B} \mathrm{N} \gamma \\
& \mathrm{qult}=1,3(2,48)(5,71)+(1,15)(1)+0 \\
& \mathrm{qult}=19,559 \mathrm{t} / \mathrm{m}^{2} \\
& \text { qall }=\mathrm{qult} / \mathrm{SF}
\end{aligned}
$$




$$
\begin{aligned}
\text { qall } & =19,559 / 3 \\
& =6,52 \mathrm{t} / \mathrm{m}^{2} \rightarrow \text { qall } \geq \text { omin } \\
& 6,52 \mathrm{t} / \mathrm{m}^{2} \geq 0,57 \mathrm{t} / \mathrm{m}^{2}(\text { ok })
\end{aligned}
$$

Kemudian dilakukan perhitungan penurunan secara elastisitas, penurunan konsolidasi, dan penurunan sekunder, yang menghasilkan nilai total penurunan yang terjadi yaitu sebagai berikut;

$$
\begin{aligned}
& \text { Se } \max =1,298 \times 10^{-4} \mathrm{~m} \\
& \text { Sc } \max =8,411 \times 10^{-3} \mathrm{~m} \\
& \text { Ss } \max =0,027 \mathrm{~m} \\
& \text { Stotal }=\mathrm{Se}+\mathrm{Sc}+\mathrm{Ss}=0,0355 \mathrm{~m} \\
& \text { Sijin }=15 \mathrm{~cm}+\mathrm{B} / 600 \\
& \quad=150+2000 / 600 \\
& \quad=153,33 \mathrm{~mm}=0,15333 \mathrm{~m}
\end{aligned}
$$

Stotal $\leq$ Sijin

$0,0355 \mathrm{~m} \leq 0,15333 \mathrm{~m}$

Karena fondasi dangkal yang direncanakan sudah memenuhi syarat dari daya dukung dan penurunan tanah, lalu kita menghitung perbandingan rencana anggaran biaya apabila fondasi dilapisi oleh epoxy dan tidak dilapisi oleh epoxy, seperti pada tabel.4 dan tabel.5 dibawah.

Tabel 4. Hasil analisis harga satuan pekerja beton fondasi per $1 \mathrm{~m}^{3}$

\begin{tabular}{lllll}
\hline $\begin{array}{l}\text { Jenis } \begin{array}{l}\text { Bahan } \\
\text { \&Tenaga }\end{array} \\
\text { Satuan }\end{array}$ & Koefisien & Harga Satuan & $\begin{array}{l}\text { Jumlah Harga } \\
(\mathrm{Rp})\end{array}$ \\
\hline Beton Cor & $\mathrm{m}^{3}$ & 1 & 505.650 & 505.650 \\
\hline Cetakan Beton & $\mathrm{m}^{2}$ & 0,7 & 76.700 & 53.690 \\
\hline Besi Beton & $\mathrm{kg}$ & 147,5 & 9.635 & 1.421 .163 \\
\hline Upah Cor & $\mathrm{m}^{3}$ & 1 & 230.000 & 230.000 \\
\hline $\begin{array}{l}\text { Buka } \\
\text { cetakan/siram }\end{array}$ & org & 1 & 30.000 & 30.000 \\
\hline
\end{tabular}


Jadi, total biaya pekerjaan fondasi: $12,35 \mathrm{~m}^{3}$ x $2.240 .503 / \mathrm{m}^{3}:$ Rp 27.670 .213 (sebelum menggunakan epoxy).

Tabel 5. Hasil analisis harga satuan pekerja beton fondasi per $1 \mathrm{~m}^{3}$

\begin{tabular}{lllll}
\hline $\begin{array}{l}\text { Jenis Bahan } \\
\text { \&Tenaga }\end{array}$ & Satuan & Koefisien & Harga Satuan & Jumlah Harga \\
& & & $(\mathrm{Rp})$ & $(\mathrm{Rp})$ \\
\hline Beton Cor & $\mathrm{m}^{3}$ & 1 & 505.650 & 505.650 \\
\hline $\begin{array}{l}\text { Cetakan } \\
\text { Beton }\end{array}$ & $\mathrm{m}^{2}$ & 0,7 & 76.700 & 53.690 \\
\hline Besi Beton & $\mathrm{kg}$ & & & \\
\hline Cat Epoxy & $\mathrm{m}^{2}$ & 147,5 & 9.635 & 3.421 .163 \\
\hline Upah Cor & $\mathrm{m}^{3}$ & 1 & 353.900 & 230.000 \\
\hline Buka & org & 1 & 230.000 & 30.000 \\
cetakan/siram & & 1 & 30.000 & 2.594 .403 \\
\hline & & & & \\
\hline
\end{tabular}

Jadi, total biaya pekerjaan fondasi: $12,35 \mathrm{~m}^{3}$ x $2.594 .403 / \mathrm{m}^{3}: \mathrm{Rp} 32.040 .878$ (memakai epoxy).

Total dari perbedaan rencana anggaran biaya kedua fondasi dapat dilihat pada tabel 6 berikut ini;

Tabel 6.Hasil perbandingan harga satuan pekerja beton fondasi

\begin{tabular}{ll}
\hline Keterangan & Harga \\
\hline Fondasi tanpa lapisan epoxy & Rp 27.670.213 \\
\hline Fondasi dengan lapisan epoxy & Rp 32.040.878
\end{tabular}

\section{KESIMPULAN DAN SARAN}

\section{Kesimpulan}

1. Hasil perhitungan daya dukung tanah dengan menggunakan daya dukung Terzaghi menyatakan bahwa, pondasi yang didesign memenuhi syarat dari daya dukung tanah secara longterm $74,406 \mathrm{t} / \mathrm{m}^{2} \geq 1,66 \mathrm{t} / \mathrm{m}^{2}$ (qall $\geq$ omax) dan shortterm $6,52 \mathrm{t} / \mathrm{m}^{2} \geq 0,57 \mathrm{t} / \mathrm{m}^{2}$ (qall $\geq \sigma \mathrm{min}$ ).

2. Hasil perhitungan penurunan didapat bahwa fondasi bujur sangkar dengan ukuran $2 \mathrm{~m} \times 2 \mathrm{~m}$ dengan kedalaman $1,5 \mathrm{~m}$ memenuhi syarat penurunan karena hasil Stotal $\leq$ Sijin, yaitu $0,0355 \mathrm{~m} \leq 0,15333 \mathrm{~m}$.

3. Hasil perhitungan perbandingan Rencana Anggaran Biaya pembuatan fondasi tanpa epoxy dan fondasi menggunakan epoxy memang memiliki perbedaan biaya yang dikeluarkan berikut hasil dari rab yang dihitung dapat dilihat pada Tabel 6. Namun, perbedaannya tidak terlalu jauh hanya saja apabila menggunakan epoxy pada beton difondasi lebih memiliki durabilitas yang cukup besar sehingga umur bangunan mampu mencapai standart yang ada yaitu sekitar 25-30 tahun. 


\section{Saran}

Pada kondisi tanah dikalimantan yang kebanyakan memiliki tingkat keasaman yang tinggi, jika tidak ingin menggunakan fondasi dangkal dapat menggantinya, menjadi fondasi yang berbahan dasar dari kayu seperti kayu ulin, dan kayu gelam. Namun kalua ingin menggunakan fondasi dangkal yang kuat terhadap asam dapat mengganti cat epoxy dengan penggunaan semen yang tahan terhadap asam yaitu, high early strength (portland cement tipe 3).

\section{DAFTAR PUSTAKA}

Construction Research Institute of Malaysia. Guidelines for Construction on Peat and Organic Soils in Malaysia. Kuala Lumpur: Construction Research Institute of Malaysia, 2015.

Hardiyatmo, H.C. Mekanika Tanah 1. Jakarta: Gramedia Pustaka Umum, 1992.

Terzaghi, Karl and Ralph Brazelton Peck. Soil Mechanics in Engineering Practise. Jakarta: Erlangga, 1967.

Yulianto, F. E. Perilaku tanah gambut berserata permasalahan dan solusinya. Jember: Jurnal Teknik Sipil Universitas Jember Konferensi Nasional Teknik Sipil dan Infrastruktur - I, 2017.

Zakaria, Z. Dayadukung Tanah Fondasi Dangkal. Sumedang: Laboratorium Geologi Teknik Jurusan Geologi, FaMIPA-UNPAD, 2006. 
Perbedaan Daya Dukung Fondasi Dangkal di Tanah

Avira Natasyah W, et al.

Gambut Dengan dan Tanpa Epoxy di Kalimantan 